\title{
Oncological Outcomes of Laparoscopic Versus Open Gastrectomy after Neoadjuvant Chemotherapy for Locally Advanced Gastric Cancer: A Retrospective Multicenter Study
}

Islam Khaled ( $\boldsymbol{\nabla}$ dr.islam.ahmed@med.suez.edu.eg )

Suez Canal University Faculty of Medicine https://orcid.org/0000-0001-6577-4312

\section{Pablo Priego}

Ramon y Cajal University Hospital: Hospital Universitario Ramon y Cajal

Hany Soliman

Cairo University Kasr Alainy Faculty of Medicine

Mohamed Faisal

Suez Canal University Faculty of Medicine

Ihab Saad

National Cancer Institute Cairo University

\section{Research Article}

Keywords: Gastric cancer, chemotherapy, laparoscopy, gastrectomy.

Posted Date: April 22nd, 2021

DOI: https://doi.org/10.21203/rs.3.rs-62349/v2

License: (c) (1) This work is licensed under a Creative Commons Attribution 4.0 International License.

Read Full License

Version of Record: A version of this preprint was published at World Journal of Surgical Oncology on July 9th, 2021. See the published version at https://doi.org/10.1186/s12957-021-02322-2. 


\section{Abstract}

Background The oncological outcomes of laparoscopic gastrectomy (LG) and open gastrectomy (OG) following neoadjuvant chemotherapy have been investigated in a few studies. Our purpose was to evaluate the oncological outcomes of $L G$ and $O G$ after neoadjuvant chemotherapy in patients with locally advanced gastric cancer (GC) and to determine the advantages, preferences, and ease of use of the two techniques after chemotherapy.

Methods We conducted a retrospective chart review of all patients who underwent either OG $(n=43)$ or LG $(n=41)$. The neoadjuvant treatment regimen consisted of capecitabine plus oxaliplatin for three cycles, which was then repeated 6 to 12 weeks after the operation for four cycles.

Results The hospital stay time and intraoperative blood loss in the LG group were significantly lower than those in the OG group. The mortality rate and the 3-year survival rate for patients in the LG group were comparable to those of patients in the OG group ( $4.6 \%$ vs. $9.7 \%$ and $68.3 \%$ vs. $58.1 \%$, respectively). Similar trends were observed regarding the 3-year recurrence rate and metastasis. The mean survival time was 52.9 months ( $95 \%$ confidence interval [Cl], 44.2-61.6) in the OG group compared with $43.3(95 \% \mathrm{Cl}$, 36.6-49.8) in the LG group. Likewise, the mean disease-free survival was 56.1 months $(95 \% \mathrm{Cl}, 46.36-$ $65.8)$ in the LG group compared with 50.9 months $(95 \% \mathrm{Cl}, 44.6-57.2)$ in the OG group.

Conclusion LG is a feasible and safe alternative to OG for patients with locally advanced GC receiving neoadjuvant chemotherapy.

\section{Introduction}

Gastric cancer (GC), which affects $>950,000$ patients annually, is the fifth most prevalent cancer and the third most common cause of cancer-related death worldwide [1-3]. Epidemiological studies have shown that the overall incidence of GC is decreasing, likely because of changes in lifestyle, such as lower salted and preserved food intake and reduced Helicobacter pylori infection. Advanced GC is identified when the tumor invades the submucosa [4]. According to the GC staging system of the American Joint Committee on Cancer, metastatic GC is stage IV $[5,6]$. The 5 -year survival after GC diagnosis ranges from $70 \%$ for stage la to $5 \%$ for stage IV [7]. In addition, the choice of the treatment strategy, such as potentially curative treatment, endoscopic treatment, or palliative treatment, depends on the disease stage.

Laparoscopic gastrectomy (LG) is one of the standard procedures for early $\mathrm{GC}$ and has also proven its feasibility in locally advanced GC [8-10]. Because of its low invasiveness, shorter hospitalization duration, faster bowel movement recovery, and good cosmetic outcomes, LG has recently gained great popularity for the management of early GC [11-13]. Many systematic reviews have proven the feasibility of LG compared with open gastrectomy (OG) in patients with GC [14-16]. Intraoperative circulatory and respiratory disturbances and the longer operative time are the main issues in LG-related difficulties; in addition, the tissue-related factors after neoadjuvant chemotherapy lead to avoidance of laparoscopic gastrectomy following neoadjuvant chemotherapy [17]. The majority of randomized clinical trials (RCTs) 
that compared LG and OG for early GC have reported early findings on the procedural safety of $L G$ and its short-term benefits [18-20]. In terms of advanced GC, there is insufficient evidence from comparisons of LG and OG, particularly in patients receiving neoadjuvant chemotherapy.

On the other hand, a multimodality approach is the cornerstone for management of patients with advanced GC. Currently, adjuvant chemotherapy is the modality recommended by both the Asian and American guidelines [21]. Recently, neoadjuvant chemotherapy has been proposed as a promising approach to improve survival compared with the adjuvant modality. Several phase III European studies have demonstrated that the administration of neoadjuvant chemotherapy prior to curative surgery and adjuvant chemotherapy in patients with GC has increased their survival rates [22, 23]. Another theoretical advantage of neoadjuvant chemotherapy is the greater probability that a multimodality approach can be successfully completed, because chemotherapy is given before any possible postoperative complications following extended surgery can develop [24]. In some patients, postoperative adjuvant chemotherapy is restricted owing to surgical complications [25].

There is an increasing interest in the safety and efficacy of LG after neoadjuvant chemotherapy. However, few studies compared the oncological outcomes of $L G$ and $O G$ after neoadjuvant chemotherapy. The edema and fibrotic tissue changes caused by chemotherapy present new technical challenges for laparoscopic treatments [26,27]. Nevertheless, many investigators have excluded patients receiving chemotherapy from studies of LG for GC. Therefore, we investigated and compared the oncological outcomes of LG and OG after neoadjuvant chemotherapy in patients with locally advanced GC.

\section{Materials And Methods}

We conducted a retrospective chart review of all adult patients ( $\geq 18$ years) of both sexes who were diagnosed with locally advanced GC and who underwent either OG or LG at Suez Canal University Hospital, Cairo University Hospitals, and Ramon y Cajal University Hospital. We excluded patients with distant metastasis or other primary malignancies as well as patients who required conversion from laparoscopic to open surgery in order to standardize the variables of the two arms of the study. The study's protocol received ethical approval from the responsible steering committee. A total of 96 patients who matched our inclusion criteria were initially screened as candidates for this study. Six patients were

excluded because they underwent palliative surgery for peritoneal dissemination, so that 90 patients were evaluated in the retrospective review. The final analysis of the included cases is illustrated in Fig. 1;84 patients ( 43 OG and $41 \mathrm{LG}$ ) were available by the end of the study.

\subsection{Preoperative Staging}

Preoperatively, we took a full patient history and performed a thorough clinical examination of all patients. In addition, we collected the findings of routine laboratory investigations, contrast-enhanced abdominal computed tomography, and upper endoscopy with tissue biopsy. Patients were clinically staged according to the TNM classification, 7th Edition [28]. The neoadjuvant treatment regimen 
consisted of capecitabine (500 mg/m $\mathrm{m}^{2}$ orally twice a day) plus oxaliplatin $\left(130 \mathrm{mg} / \mathrm{m}^{2}\right)$ for three cycles (21 days in each cycle). This was repeated 6 to 12 weeks after the operation for four cycles. The radiological response to the neoadjuvant chemotherapy was assessed according to the Response Evaluation Criteria in Solid Tumors (version 1.1) [29]. The severity of the chemotherapy-associated adverse events was assessed according to the recommendations of the Common Terminology Criteria for Adverse Events (version 4.0) [30].

\subsection{Surgical Technique}

The surgery was performed within 4 to 6 weeks after the completion of the chemotherapy. Prophylactic 3rd generation cephalosporin antibiotics were given simultaneously after general anesthesia to all patients, and a Foley catheter was inserted.

A standard LG or OG with appropriate lymphadenectomy according to the Japanese classification of gastric carcinoma (including lymph nodes $1-9,11 p$, and 12a in D2 lymphadenectomy and 1-8a and 12a in extended D1 lymphadenectomy) was performed by an experienced surgeon [31].

In both OG or LG groups, an initial exploration was conducted to assess the feasibility of the resection. In the OG group, a 20- to $25-\mathrm{cm}$ midline incision was made from the xiphoid process to the periumbilical area. In the LG group, 4-mm periumbilical ports were inserted in the left upper quadrant and the right and left flank areas. Another 5-mm port was inserted in the right upper quadrant. In both groups, the decision to perform either a subtotal or total resection was based solely on the tumor site and extent. In cases in which the upper one-third of the greater curvature was involved, the spleen was resected. Roux-en-Y procedures, with functional side-to-side anastomoses, were performed to restore the continuity of the gastrointestinal tract. The specimen was pulled out through a small median incision under the xiphoid (approximately $6-8 \mathrm{~cm}$ ).

Postoperative management was done according to the participating hospitals' guidelines. Patients were discharged after $>2$ days of soft diet without fever or abdominal pain. The adjuvant regimen started on the beginning of the seventh postoperative week and consisted of oxaliplatin plus capecitabine for five cycles. Dose reduction or treatment discontinuation was attempted in cases of serious adverse events. In addition, oxaliplatin was stopped if there were neurological complications. Palliative and supportive care was offered as needed for disease-related symptoms.

\subsection{Follow-Up and Study End Points}

Patients were followed up during their hospital stay and for 3 years after the procedure. The primary objective was to compare the 3-year survival rate and overall survival (OS) between the LG and OG groups. Secondary end points included survival time, 3-year recurrence rate, disease progression-free survival (DFS), operative time, intraoperative blood loss, hospital stay, and postoperative complications. The complications were assessed using Clavien-Dindo grades, in which 1 of 5 grades was allocated according to the type of management of the complication [32].

\subsection{Statistical Analysis}


Statistical data analysis was conducted using Microsoft Excel 2013 (Microsoft Corp., Redmond, WA) 32bit software. Continuous data were expressed as means ( \pm standard deviation [SD]), and categorical data were described as percentages. Comparisons between qualitative data were performed using the chisquare or Fisher's exact tests, whereas comparisons between quantitative data were performed using the Mann-Whitney or analysis of variance tests. A $P$ value of $<5 \%$ was considered statistically significant.

\section{Results}

In the current study, the mean age ( \pm SD) of the evaluated patients was $64.0 \pm 10.7$ years in the $O G$ group and $62.3 \pm 4.5$ years in the $\mathrm{LG}$ group $(P=0.45)$. There was male predominance in the OG group but not in the LG group (60.5\% and $48.8 \%$, respectively; $P=0.29$ ). Additionally, there were no significant differences between the groups in terms of the tumor site $(P=0.28)$, tumor differentiation $(P=0.15)$, and clinical stage $(P=0.52)$. On the other hand, the frequency of radiological complete response was significantly higher in the OG group than that in the LG group ( $39.5 \%$ vs. $24.4 \%$, respectively; $P=0.002$ ) (Table 1$)$. 
Table 1

Preoperative data of the studied gastrectomy groups.

\begin{tabular}{|c|c|c|c|}
\hline Variables & OG Group $(n=43)$ & LG Group $(n=41)$ & $P$ value \\
\hline Age (mean \pm standard deviation), years & $64 \pm 10.7$ & $62.29 \pm 4.5$ & 0.45 \\
\hline Male, no (\%) & $26(60.5 \%)$ & $20(48.8 \%)$ & 0.29 \\
\hline Tumor site & $6(14 \%)$ & $9(22 \%)$ & 0.28 \\
\hline - Esophagogastric junction & $2(4.7 \%)$ & $4(9.8 \%)$ & \\
\hline - Fundus & $21(48.8 \%)$ & $11(26.8 \%)$ & \\
\hline - Body & $12(27.9 \%)$ & $13(31.7 \%)$ & \\
\hline - Antrum & $2(4.7 \%)$ & $4(9.8 \%)$ & \\
\hline \multicolumn{4}{|l|}{ - Pylorus } \\
\hline Tumor differentiation & $8(18.6 \%)$ & $4(9.8 \%)$ & 0.15 \\
\hline - Well & $10(23.3 \%)$ & $15(36.6 \%)$ & \\
\hline - Moderate & $22(51.2 \%)$ & $22(53.7 \%)$ & \\
\hline \multicolumn{4}{|l|}{ - Poor } \\
\hline Tumor stage & $15(34.9 \%)$ & $15(36.6 \%)$ & 0.52 \\
\hline$\cdot \|$ & $28(65.1 \%)$ & $26(63.4 \%)$ & \\
\hline \multicolumn{4}{|l|}{ • III } \\
\hline T stage & $12(27.9 \%)$ & $10(24.3 \%)$ & 0.56 \\
\hline$\cdot$ T2 & $17(39.5 \%)$ & $20(48.7 \%)$ & \\
\hline$\cdot$ T3 & $11(47.2 \%)$ & 11 (26.8\%) & \\
\hline$\cdot$ T4a & 3 (6.9\%) & $0(0.0 \%)$ & \\
\hline \multicolumn{4}{|l|}{$\cdot \mathrm{T} 4 \mathrm{~b}$} \\
\hline $\mathrm{N}$ stage & $12(27.9 \%)$ & $21(51.2 \%)$ & 0.14 \\
\hline - NO & $9(20.9 \%)$ & $9(22 \%)$ & \\
\hline$\cdot \mathrm{N} 1$ & $10(23.3 \%)$ & $7(17.1 \%)$ & \\
\hline - N2 & 8 (18.6\%) & 4 (9.8\%) & \\
\hline - N3a & $3(7 \%)$ & $0(0.0 \%)$ & \\
\hline - N3b & & & \\
\hline
\end{tabular}




\begin{tabular}{|llll|}
\hline Variables & OG Group $(\mathrm{n}=43)$ & LG Group $(\mathrm{n}=\mathbf{4 1})$ & Pvalue \\
\hline Radiological response & $17(39.5 \%)$ & $10(24.4 \%)$ & $0.002^{*}$ \\
$\cdot$ CR & $14(32.6 \%)$ & $9(22.0 \%)$ & \\
$\cdot$ PD & $12(27.9 \%)$ & $10(24.4 \%)$ & \\
$\cdot$ SD & & & \\
\hline
\end{tabular}

In terms of intraoperative characteristics, intraoperative blood loss was significantly lower in the LG group than in the $O G$ group $(70.5 \pm 28.1 \mathrm{~mL}$ vs. $157.2 \pm 17.6 \mathrm{~mL}$, respectively; $P=0.012)$. No significant differences were detected between the $O G$ and $L G$ groups regarding the operation time $(P=0.202)$, extent of resection $(P=0.19)$, margin of resection $(P=0.64)$, number of total lymph nodes $(P=0.17)$, and number of positive lymph nodes $(P=0.14)$ (Table 2$)$. There were only four patients in whom LG was converted to open surgery because of marked adhesions and difficult anatomical orientation and only one case because of a large matted lymph node in station VIII, which was difficult to dissect. 
Table 2

Intraoperative data of the studied gastrectomy groups.

\begin{tabular}{|c|c|c|c|}
\hline Variables & OG Group $(n=43)$ & LG Group $(n=41)$ & $P$ value \\
\hline $\begin{array}{l}\text { Duration of operation, min } \\
\text { (mean } \pm S D)\end{array}$ & $279.9 \pm 70.8$ & $297.8 \pm 56.2$ & 0.202 \\
\hline $\begin{array}{l}\text { Extent of resection, no. (\%) } \\
\text { - Distal subtotal } \\
\text { - Total }\end{array}$ & $\begin{array}{l}16(37.2 \%) \\
27(62.8 \%)\end{array}$ & $\begin{array}{l}15(36.6 \%) \\
26(63.4 \%)\end{array}$ & 0.19 \\
\hline $\begin{array}{l}\text { Margin of resection, no. (\%) } \\
\cdot \text { R0 } \\
\text { - R1 }\end{array}$ & $\begin{array}{l}40(93 \%) \\
3(7 \%)\end{array}$ & $\begin{array}{l}37(90.2 \%) \\
4(9.8 \%)\end{array}$ & 0.64 \\
\hline $\begin{array}{l}\text { Type of positive margin, no. (\%) } \\
\text { - Proximal } \\
\text { • Distal }\end{array}$ & $\begin{array}{l}2(4.7 \%) \\
1(2.3 \%)\end{array}$ & $\begin{array}{l}2(4.9 \%) \\
2(4.9 \%)\end{array}$ & 0.78 \\
\hline $\begin{array}{l}\text { Lymphadenectomy type, no. (\%) } \\
\text { • D1+ } \\
\text { •D2 } \\
\text { - D2+ }\end{array}$ & $\begin{array}{l}16(37.2 \%) \\
21(48.8 \%) \\
6(14 \%)\end{array}$ & $\begin{array}{l}16(39 \%) \\
22(53.6 \%) \\
3(7.3 \%)\end{array}$ & 0.142 \\
\hline $\begin{array}{l}\text { Blood loss, mL } \\
\text { (mean } \pm \text { SD) }\end{array}$ & $157.2 \pm 17.65$ & $70.5 \pm 28.12$ & 0.012 \\
\hline $\begin{array}{l}\text { No. of total lymph nodes } \\
\text { (mean } \pm \text { SD) }\end{array}$ & $27.6 \pm 16.5$ & $21.6 \pm 10.3$ & 0.17 \\
\hline $\begin{array}{l}\text { No. of positive lymph nodes } \\
\text { (mean } \pm \text { SD) }\end{array}$ & $4.4 \pm 8$ & $2.9 \pm 4.4$ & 0.14 \\
\hline
\end{tabular}

The hospital stay was significantly shorter in the LG group than in the OG group ( $4.75 \pm 5.17$ days vs. $8.11 \pm 2.44$ days, respectively; $P=0.026$ ). The mortality rate was comparable for patients in the $O G$ group and the patients in the LG group ( $9.7 \%$ vs. $4.6 \%$, respectively; $P=0.36)$. Septic peritonitis and anastomosis leakage were the causes of death in two patients in the OG group, whereas the cause of death was general in the rest of the patients. Patients in the LG group showed a lower rate of postoperative complications; however, this did not reach the level of statistical significance $(P=0.16)$. The types of postoperative complications were comparable between the two groups $(P=0.128)$. Patients in the $L G$ 
group were less likely to experience high Clavien-Dindo grade complications than patients in the OG group $(P=0.026)$ (Table 3$)$.

Table 3

Postoperative data of the studied gastrectomy groups.

\begin{tabular}{|c|c|c|c|}
\hline Variables & OG Group $(n=43)$ & LG Group $(n=41)$ & $P$ value \\
\hline \multicolumn{4}{|l|}{$($ mean $\pm S D)$} \\
\hline Mortality, no. (\%) & $4(9.7 \%)$ & $2(4.6 \%)$ & 0.36 \\
\hline Postoperative complications, no. (\%) & $7(17.1 \%)$ & $8(19.5 \%)$ & 0.16 \\
\hline Type of surgical complications, no. (\%) & $0(0 \%)$ & $2(4.7 \%)$ & \multirow[t]{7}{*}{0.128} \\
\hline - Abdominal collection & $4(9.8 \%)$ & $3(7 \%)$ & \\
\hline • Esophagojejunal leak & $1(2.4 \%)$ & $0(0 \%)$ & \\
\hline - Gastrointestinal bleeding & $0(0 \%)$ & $1(2.3 \%)$ & \\
\hline -Wound infection & $1(2.4 \%)$ & $0(0 \%)$ & \\
\hline - Intraperitoneal bleeding & $0(0 \%)$ & $2(4.7 \%)$ & \\
\hline \multicolumn{3}{|l|}{ - Pancreatic leak } & \\
\hline Type of medical complications, no. (\%) & $2(4.6 \%)$ & $0(0 \%)$ & \multirow[t]{7}{*}{0.227} \\
\hline - Urinary tract infection & $1(2.3 \%)$ & $0(0 \%)$ & \\
\hline - Enteritis & $0(0 \%)$ & $1(2.4 \%)$ & \\
\hline - Gastrointestinal bleeding & $3(7 \%)$ & $1(2.4 \%)$ & \\
\hline - Pleural effusion & $1(2.3 \%)$ & $0(0 \%)$ & \\
\hline - Pulmonary embolism & $0(0 \%)$ & $1(2.4 \%)$ & \\
\hline \multicolumn{3}{|l|}{ - Sepsis } & \\
\hline Clavien-Dindo class, no. (\%) & $2(4.9 \%)$ & $8(18.6 \%)$ & \multirow[t]{6}{*}{0.026} \\
\hline - Grade II & $1(2.4 \%)$ & $4(9.3 \%)$ & \\
\hline - Grade IIIA & $2(4.9 \%)$ & $0(0 \%)$ & \\
\hline - Grade IIIB & $1(2.4 \%)$ & $0(0 \%)$ & \\
\hline - Grade IVA & $2(4.9 \%)$ & $0(0 \%)$ & \\
\hline - Grade V & & & \\
\hline Reintervention, no. (\%) & $2(4.7 \%)$ & $2(4.9 \%)$ & 0.96 \\
\hline
\end{tabular}


Regarding long-term outcomes, the 3-year survival rate was comparable between the OG and LG groups (58.1\% vs. $68.3 \%$, respectively; $P=0.23)$. Similar trends were observed for the 3 -year recurrence rate $(P=$ 0.15 ) and metastasis $(P=0.26)$ (Table 4$)$. The mean survival time was 52.9 months ( $95 \%$ confidence interval [CI], 44.2-61.6) in the OG group vs. 43.3 months $(95 \% \mathrm{Cl}, 36.6-49.8)$ in the LG group $(P=0.96)$ (Fig. 2). Likewise, the mean DFS was 56.1 months $(95 \% \mathrm{Cl}, 46.4-65.8)$ in the $\mathrm{LG}$ group vs. 50.9 months $(95 \% \mathrm{Cl}, 44.6-57.2)$ in the OG group $(P=0.218)$ (Fig. 3).

Table 4

3-year outcomes of the studied gastrectomy groups.

\begin{tabular}{|llll|}
\hline Variables & OG Group $(\mathbf{n = 4 3 )}$ & LG Group (n= 41) & P value \\
\hline Metastasis, no. (\%) & $8(18.6 \%)$ & $2(4.9 \%)$ & 0.26 \\
• Locoregional & $1(2.3 \%)$ & $1(2.4 \%)$ & \\
- Liver & $4(9.3 \%)$ & $2(4.9 \%)$ & \\
- Carcinomatosis & $1(2.3 \%)$ & $0(0.0 \%)$ & \\
- Anastomosis & & & \\
\hline Recurrence (No., \%) & $13(30.3 \%)$ & $6(14.6 \%)$ & 0.15 \\
\hline Overall Survival (No., \%) & $25(58.1 \%)$ & $28(68.3 \%)$ & 0.23 \\
\hline
\end{tabular}

Cox regression analysis demonstrated that none of the perioperative characteristics was an independent predictor of OS. On the other hand, age younger $<70$ years old (hazard ratio, $0.015 ; 95 \% \mathrm{Cl}, 0-0.65$ ) was an independent predictor of favorable DFS (Table 5). 
Table 5

Cox regression analysis of predictors of overall survival (OS) and disease progression-free survival (DFS)

\begin{tabular}{|c|c|c|c|c|}
\hline \multirow[t]{2}{*}{ Variables } & \multicolumn{2}{|l|}{ OS } & \multicolumn{2}{|l|}{ DFS } \\
\hline & $\mathrm{HR}(95 \% \mathrm{Cl})$ & $\begin{array}{l}P \\
\text { value }\end{array}$ & $\mathrm{HR}(95 \% \mathrm{Cl})$ & $\begin{array}{l}\mathrm{P} \\
\text { value }\end{array}$ \\
\hline Age $\geq 70$ years & $1.16(.995-1.25)$ & 0.06 & $1.152(1.025-1.29)$ & 0.017 \\
\hline Male sex & $\begin{array}{l}0.584(0.062- \\
5.466)\end{array}$ & 0.63 & $\begin{array}{l}0.736(0.041- \\
13.287)\end{array}$ & 0.83 \\
\hline Differentiation (moderate) & $\begin{array}{l}0.749(0.007- \\
78.71)\end{array}$ & 0.93 & $1.117(0.001-17.07)$ & 0.39 \\
\hline Differentiation (poor) & $\begin{array}{l}1.277(0.018- \\
4.249)\end{array}$ & 0.35 & $1.084(0.002-2.86)$ & 0.16 \\
\hline Tumor stage III & $1.66(0.23-1.92)$ & 0.45 & $1.228(0.34-1.2)$ & 0.081 \\
\hline $\begin{array}{l}\text { Radiological response (CR vs. } \\
\text { SD/PD) }\end{array}$ & $0.65(025-1.69)$ & 0.37 & $0.31(0.06-2.8)$ & 0.285 \\
\hline Laparoscopic gastrectomy & $\begin{array}{l}0.685(0.112- \\
4.201)\end{array}$ & 0.68 & $1.879(0.092-38.47)$ & 0.113 \\
\hline Total gastrectomy (distal vs. total) & $\begin{array}{l}1.299(0.234- \\
7.198)\end{array}$ & 0.76 & $3.9(0.34-46.45)$ & 0.274 \\
\hline Locoregional metastasis & $\begin{array}{l}1.081(0.1- \\
42.427)\end{array}$ & 0.43 & $\begin{array}{l}4.842(0.075- \\
313.77)\end{array}$ & 0.45 \\
\hline Distant metastasis & $4.53(0.58-35.35)$ & 0.15 & $\begin{array}{l}23.479(0.982- \\
561.12)\end{array}$ & 0.051 \\
\hline $\mathrm{R} 1$ marginal resection & $2.45(0.29-20.29)$ & 0.41 & $0.019(0-2.4)$ & 0.111 \\
\hline Complications (yes vs. no)- & $\begin{array}{l}0.168(0.014- \\
1.99)\end{array}$ & 0.16 & $2.470(0.171-35.74)$ & 0.51 \\
\hline Reintervention (yes vs. no) & $\begin{array}{l}35.56(3.39- \\
372.19)\end{array}$ & 0.003 & 2.934 & 0.997 \\
\hline Laparoscopic gastrectomy & $\begin{array}{l}1.016(0.49- \\
2.098)\end{array}$ & 0.96 & $0.858(0.418-1.759)$ & 0.67 \\
\hline
\end{tabular}

\section{Discussion}

Owing to the aggressive nature of the disease, old age in the majority of cases, poor nutrition, extreme radical dissection, and surgical trauma, patients with locally advanced GC are prone to prolonged hospital stays, postoperative morbidity, increased financial burden, and even a high risk of postoperative 
mortality [33]. Thus, in patients with GC, surgeons must take care when choosing the treatment strategy [33]. This makes LG the fastest growing minimally invasive procedure for patients with GC [34].

Several trials have shown that $L G$ is associated with smaller incisions, reduced bleeding, and decreased surgical stress $[35,36]$. However, despite the great advances in this technique and its impact on oncological outcomes, LG has some issues, such as decreased intraoperative lung compliance owing to the establishment of artificial pneumoperitoneum as well as the relatively long operative time required for this procedure [37]. Therefore, some researchers have suggested using neoadjuvant chemotherapy before LG or OG because the chemotherapy may help prevent an unnecessary procedure by reducing the tumor size and making R0 resection easier. In addition, micrometastatic tumor cell eradication can begin at an early stage, which is an important advantage over adjuvant chemotherapy $[25,38]$.

Our findings highlighted the differences between LG and OG in two groups of matched patients with GC. In agreement with the literature, our findings showed that LG was associated with less intraoperative blood loss $(P=0.012)$, shorter hospitalization $(P=0.026)$, and a lower rate of postoperative complications $(P=0.16)$. On the other hand, the in-hospital mortality rate and types of postoperative complications were comparable in both groups. Regarding long-term outcomes, both groups were comparable in terms of 3year survival $(P=0.23)$, mean survival time $(P=0.96)$, 3-year recurrence rate $(P=0.15)$, and metastasis ( $P$ $=0.26)$. LG had a higher DFS, but this was not statistically significant $(P=0.218)$. These findings indicated that LG had more favorable intra- and postoperative outcomes in terms of safety and tolerability. However, the efficacy of LG compared with OG remains controversial.

The Korean Laparoendoscopic Gastrointestinal Surgery Study trial demonstrated that laparoscopic distal gastrectomy and open distal gastrectomy were almost similar in terms of 5 -year survival $(94.2 \% \mathrm{vs}$. $93.3 \%$, respectively; $P=0.64)$ and 5 -year cancer-specific survival rates $(97.1 \%$ vs. $97.2 \%$, respectively; $P=$ 0.91). Both groups were comparable concerning total deaths and recurrence $(P=0.49$ and $P=0.60$, respectively) [35]. There were doubts about the oncological safety of LG for GC, as the risk of locoregional recurrence was potentially increased owing to insufficient lymphadenectomy [14]. An RCT conducted by Hu et al. showed similar rates of D2 lymphadenectomy for LG and OG (99.4\% vs. $99.6 \%$, respectively; $P=$ $0.845)$ and comparable postoperative morbidity $(15.2 \%$ vs. $12.9 \%$, respectively; $P=0.28)$ and mortality ( $0.4 \%$ vs. $0 \%$, respectively; $P=0.24$ ) [39]. In agreement with our findings, Yu et al. showed a similar 3-year DFS rate for LG (76.5\%) and OG (77.8\%) in patients with locally advanced GC. Furthermore, the 3-year OS rate, recurrence rate, and mortality rate were comparable for the two groups $(P=0.28, P=0.35$, and $P=$ 0.33 , respectively) [19]. In the retrospective analysis by Fujisaki et al., they reported comparable 5-year DFS $(44.4 \%$ vs. $53.3 \% ; P=0.382)$ and OS $(46.9 \%$ vs. $54.0 \% ; P=0.422)$ in the $L G$ and OG groups, respectively [40].

Anastomotic leakage and septic peritonitis are considered the major complications of gastric surgery. In our study, these two complications were the causes of death of two patients in the LG group. Hu et al. reported the anastomotic leakage rate in their LG group was $1.9 \%$ [39], which was within the previously reported range $[18,20,41,42]$. This differed from the research results of Rod et al., who reported a high 
anastomotic leakage rate in the LG group (17\%), especially in comparison with the rate in the OG group (10\%). The overall incidences of postoperative complications (57\% vs. $48 \% ; P=0.128)$ and surgical complications ( $48 \%$ vs. $27 \% ; P=0.005$ ) were higher in the $L G$ group than in the OG group, but postoperative mortality did not differ significantly between the groups [43]. Similarly, Haverkamp et al. reported a $37 \%$ complication rate in their LG group [44].

A recent meta-analysis of 15 studies showed that LG was associated with decreased intraoperative blood loss (mean difference [MD], $-76.95 \mathrm{~mL} ; P<0.001$ ), shorter postoperative hospital stay (MD, - 2.84 days; $P<0.001)$, and shorter time to first oral intake (MD, -0.88 days; $P<0.001)$ compared with results for OG. On the other hand, $L G$ had a longer operative time and comparable postoperative mortality rate compared with OG [45]. Another meta-analysis of seven studies showed that LG was associated with decreased blood loss (MD, $-127.47 \mathrm{~mL} ; P=0.0009)$, shorter hospital stay (MD, -5.26 days; $P<0.0001)$, shorter time to first oral intake (MD, -0.94 days; $P<0.0001)$, time to first flatus (MD, -1.04 days; $P<0.0001)$, and time to first ambulation (MD, -2.07 days; $P<0.0001)$, but longer operative time (MD, $15.73 \mathrm{~min} ; P=0.001)$ compared with OG. Regarding overall postoperative complications, surgical complications, medical complications, and pulmonary infections, LG showed favorable results compared with OG. However, in terms of the number of harvested lymph nodes, both groups were comparable $(P=0.11)$ [15].

Li et al. showed that after four cycles of neoadjuvant chemotherapy (SOX, CAPOX, or FOLFOX7 regimens), LG and OG were comparable in terms of distal and proximal margins, number of resected or metastatic lymph nodes, postoperative complications, operative time, blood loss, and length of hospital stay [25]. After 3 years, they published an RCT showing that, among 95 patients with GC who were receiving neoadjuvant chemotherapy before surgery, the LG group had a substantially lower postoperative complication rate than that of the OG group ( $20 \%$ vs. $46 \%$, respectively; $P=0.007)$. Moreover, $L G$ was associated with a lower postoperative pain score (visual analog scale) compared with that of OG (1.5 vs. 3 , respectively; $P=0.04$ ) [46]. Wu et al. compared two groups of GC patients. The first group received neoadjuvant chemotherapy before undergoing surgery, and the second group was assigned to surgery directly. Total blood loss in the neoadjuvant group was substantially higher than that of the other group (320.79 vs. $243.37 \mathrm{~mL}$, respectively; $P<0.04)$. However, operative time $(P=0.65)$, lymph nodes harvested $(P=0.25)$, multiorgan resection $(P=0.054)$, and postoperative complications $(P=0.361)$ were comparable between the two groups. [47].

In locally advanced GC, pooling of five trials demonstrated that overall short-term morbidity and mortality of LG with D2 lymphadenectomy were equivalent to those with OG [16]. On the other hand, Best et al. found no significant difference in short- and long-term results between LG and OG [48]. They disagreed with previous systematic reviews $[13,49,50]$ that concluded that $L G$ is better than $O G$, and they believed that this conclusion was based on weak and heterogeneous studies.

\section{Conclusion}


LG for patients with locally advanced GC who have received neoadjuvant chemotherapy is a safe and feasible alternative to OG. LG showed reduced blood loss, better postoperative healing, and lower postoperative morbidity relative to OG. Nonetheless, well-designed RCTs for further validation are still required. The direct impact of neoadjuvant chemotherapy on LG or OG should be investigated by comparing patients who received neoadjuvant therapy before surgery with those who were assigned to surgery directly.

\section{Declarations}

\section{Ethical Standards}

All procedures followed were in accordance with the ethical standards of the Suez Canal University Hospital ethical committee on 17/11/2018 (reference \#3374) Ramon y Cajal University Hospital and Cairo University ethics committee and with the Helsinki Declaration of 1964 and later versions. An informed written and verbal consent was obtained from all the studied patients.

\section{Availability of data and materials}

The datasets used and/or analyzed during the current study are available from the corresponding author on reasonable request. All data generated or analyzed during this study are included in this published article [and its supplementary information files].

\section{Conflict of interests}

The authors declare that they have no conflicts of interests.

\section{Consent of publication:}

All authors declare that a written and verbal informed consent was obtained from the selected participants in the study for publication of the data.

\section{Funding}

No funding was received.

\section{Authors' contributions}

IK, PP \& IS carried out the surgical procedures, HS carried out the preoperative protocol for neoadjuvant chemotherapy and followed the patients later, IK, IS, PP \& MF drafted the manuscript conceived the study, participated in study design and sequence alignment, and drafted the manuscript. IS, HS \& MF helped to draft and critically revise the manuscript. IK, HS, PP \& MF participated in data collection and performance of the statistical analysis. All authors participated in study coordination, and critical revision and have read and approved the final manuscript. 
Acknowledgments

We would like to give special thanks, admiration, and respect to all our departments members for their kind help, guidance and valuable support.

\section{References}

[1] Figueiredo T, Guedes MTS, Souza LPSe, Rosa AAS, Accetta AC, de Luca Nascimento MA, et al. Prevalence of family history of cancer among gastric cancer patients at Brazilian National Cancer Institute. Health;09:25-37 2017. https://doi.org/10.4236/health.2017.91003.

[2] Goetze OT, Al-Batran SE, Chevallay M, Mönig SP. Multimodal treatment in locally advanced gastric cancer. Update Surg;70:173-9 2018. https://doi.org/10.1007/s13304-018-0539-z.

3] World Cancer Research Fund. Continuous Update Project Report: Diet, Nutrition, Physical activity and Stomach cancer. STOMACH CANCER Rep. International/American Institute for Cancer Research;2016.

[4] Boussios S, Seraj E, Zarkavelis G, Petrakis D, Kollas A, Kafantari A, et al. Management of patients with recurrent/advanced cervical cancer beyond first line platinum regimens: Where do we stand? A literature review. Crit Rev Oncol Hematol;108:164-74 2016.

https://doi.org/10.1016/j.critrevonc.2016.11.006.

[5] Lee MH, Choi D, Park MJ, Lee MW. Gastric cancer: Imaging and staging with MDCT based on the 7th AJCC guidelines. Abdom Imaging;37:531-40 2012. https://doi.org/10.1007/s00261-011-9780-3.

[6] Egner JR. AJCC cancer staging manual. JAMA;304 2010. https://doi.org/10.1001/jama.2010.1525.

[7] Washington K 7th edition of the AJCC cancer staging manual: Stomach. Ann Surg Oncol;17:30779 2010. https://doi.org/10.1245/s10434-010-1362-z.

[8] Chen K, Mou YP, Xu XW, Pan Y, Zhou YC, Cai JQ, Huang CJ. Comparison of short-term surgical outcomes between totally laparoscopic and laparoscopic-assisted distal gastrectomy for gastric cancer: A 10-y single-center experience with meta-analysis. J Surg Res;194:367-74 2015. https://doi.org/10.1016/j.jss.2014.10.020.

[9] Mochiki E, Kamiyama Y, Aihara R, Nakabayashi T, Asao T, Kuwano H. Laparoscopic assisted distal gastrectomy for early gastric cancer: Five years' experience. Surgery;137:317-22 2005. https://doi.org/10.1016/j.surg.2004.10.012.

[10] Lee SIl, Choi YS, Park DJ, Kim HH, Yang HK, Kim MC. Comparative study of laparoscopy-assisted distal gastrectomy and open distal gastrectomy. J Am Coll Surg;202:874-80 2006. https://doi.org/10.1016/j.jamcollsurg.2006.02.028. 
[11] Haverkamp L, Brenkman HJF, Seesing MFJ, Gisbertz SS, van Berge Henegouwen MI, Luyer MDP, et al. Laparoscopic versus open gastrectomy for gastric cancer, a multicenter prospectively randomized controlled trial (LOGICA-trial). BMC Cancer;15:556 2015. https://doi.org/10.1186/s12885-015-1551-z.

[12] Lin JX, Huang CM, Zheng CH, Li P, Xie JW, Wang JB, et al. Surgical outcomes of 2041 consecutive laparoscopic gastrectomy procedures for gastric cancer: A large-scale case control study. PLOS ONE;10:e0114948 2015. https://doi.org/10.1371/journal.pone.0114948.

[13] Sun J, Li J, Wang J, Pan T, Zhou J, Fu X, Zhang S. Meta-analysis of randomized controlled trials on laparoscopic gastrectomy vs. open gastrectomy for distal gastric cancer.

Hepatogastroenterology;59:1699-705 2012. https://doi.org/10.5754/hge12259.

[14] Memon MA, Khan S, Yunus RM, Barr R, Memon B. Meta-analysis of laparoscopic and open distal gastrectomy for gastric carcinoma. Surg Endosc;22:1781-9 2008. https://doi.org/10.1007/s00464-0089925-9.

[15] Wang JF, Zhang SZ, Zhang NY, Wu ZY, Feng JY, Ying LP, Zhang JJ. Laparoscopic gastrectomy versus open gastrectomy for elderly patients with gastric cancer: A systematic review and meta-analysis. World J Surg Oncol;14:90 2016. https://doi.org/10.1186/s12957-016-0859-8.

[16] Beyer K, Baukloh AK, Kamphues C, Seeliger H, Heidecke CD, Kreis ME, Patrzyk M. Laparoscopic versus open gastrectomy for locally advanced gastric cancer: A systematic review and meta-analysis of randomized controlled studies. World J Surg Oncol;17:68 2019. https://doi.org/10.1186/s12957-0191600-1.

[17] Neudecker J, Sauerland S, Neugebauer E, Bergamaschi R, Bonjer HJ, Cuschieri A, et al. The European Association for Endoscopic Surgery clinical practice guideline on the pneumoperitoneum for laparoscopic surgery. Surg Endosc;16:1121-43 2002. https://doi.org/10.1007/s00464-001-9166-7.

[18] Kim MC, Kim W, Kim HH, Ryu SW, Ryu SY, Song KY, et al. Risk factors associated with complication following laparoscopy-assisted gastrectomy for gastric cancer: A large-scale Korean multicenter study. Ann Surg Oncol;15:2692-700 2008. https://doi.org/10.1245/s10434-008-0075-z.

19] Yu J, Huang $\mathrm{C}$, Sun $Y$, Su $X, \mathrm{Cao} H, \mathrm{Hu} J$, et al. Effect of laparoscopic vs open distal gastrectomy on 3-year disease-free survival in patients with locally advanced gastric cancer: The CLASS-01 randomized clinical trial. JAMA;321:1983-92 2019. https://doi.org/10.1001/jama.2019.5359.

[20] Park DJ, Han SU, Hyung WJ, Kim MC, Kim W, Ryu SY, et al. Long-term outcomes after laparoscopyassisted gastrectomy for advanced gastric cancer: A large-scale multicenter retrospective study. Surg Endosc;26:1548-53 2012. https://doi.org/10.1007/s00464-011-2065-7.

[21] Newton AD, Datta J, Loaiza-Bonilla A, Karakousis GC, Roses RE. Neoadjuvant therapy for gastric cancer: Current evidence and future directions. J Gastrointest Oncol;6:534-43 2015. 
https://doi.org/10.3978/j.issn.2078-6891.2015.047.

[22] Cunningham D, Allum WH, Stenning SP, Thompson JN, Van De Velde CJH, Nicolson M, et al. Perioperative chemotherapy versus surgery alone for resectable gastroesophageal cancer. N Engl J Med;355:11-20 2006. https://doi.org/10.1056/NEJMoa055531.

[23] Ychou M, Boige V, Pignon JP, Conroy T, Bouché O, Lebreton G, et al. Perioperative chemotherapy compared with surgery alone for resectable gastroesophageal adenocarcinoma: An FNCLCC and FFCD multicenter phase III trial. J Clin Oncol;29:1715-21 2011. https://doi.org/10.1200/JC0.2010.33.0597.

[24] Ott K, Lordick F, Herrmann K, Krause BJ, Schuhmacher C, Siewert JR. The new credo: Induction chemotherapy in locally advanced gastric cancer: Consequences for surgical strategies. Gastric Cancer;11:1-9 2008. https://doi.org/10.1007/s10120-007-0448-1.

[25] Li Z, Shan F, Wang Y, Li S, Jia Y, Zhang L, et al. Laparoscopic versus open distal gastrectomy for locally advanced gastric cancer after neoadjuvant chemotherapy: Safety and short-term oncologic results. Surg Endosc;30:4265-71 2016. https://doi.org/10.1007/s00464-015-4739-z.

[26] Zhou D lei, Zheng C zhu. Li J hui, Yin K, Ke C wei, Liu H tao, et al. Application of neoadjuvant chemotherapy in laparoscopic gastrectomy for advanced gastric cancer. Zhonghua wei chang wai ke za zhi 2009.

\section{Figures}




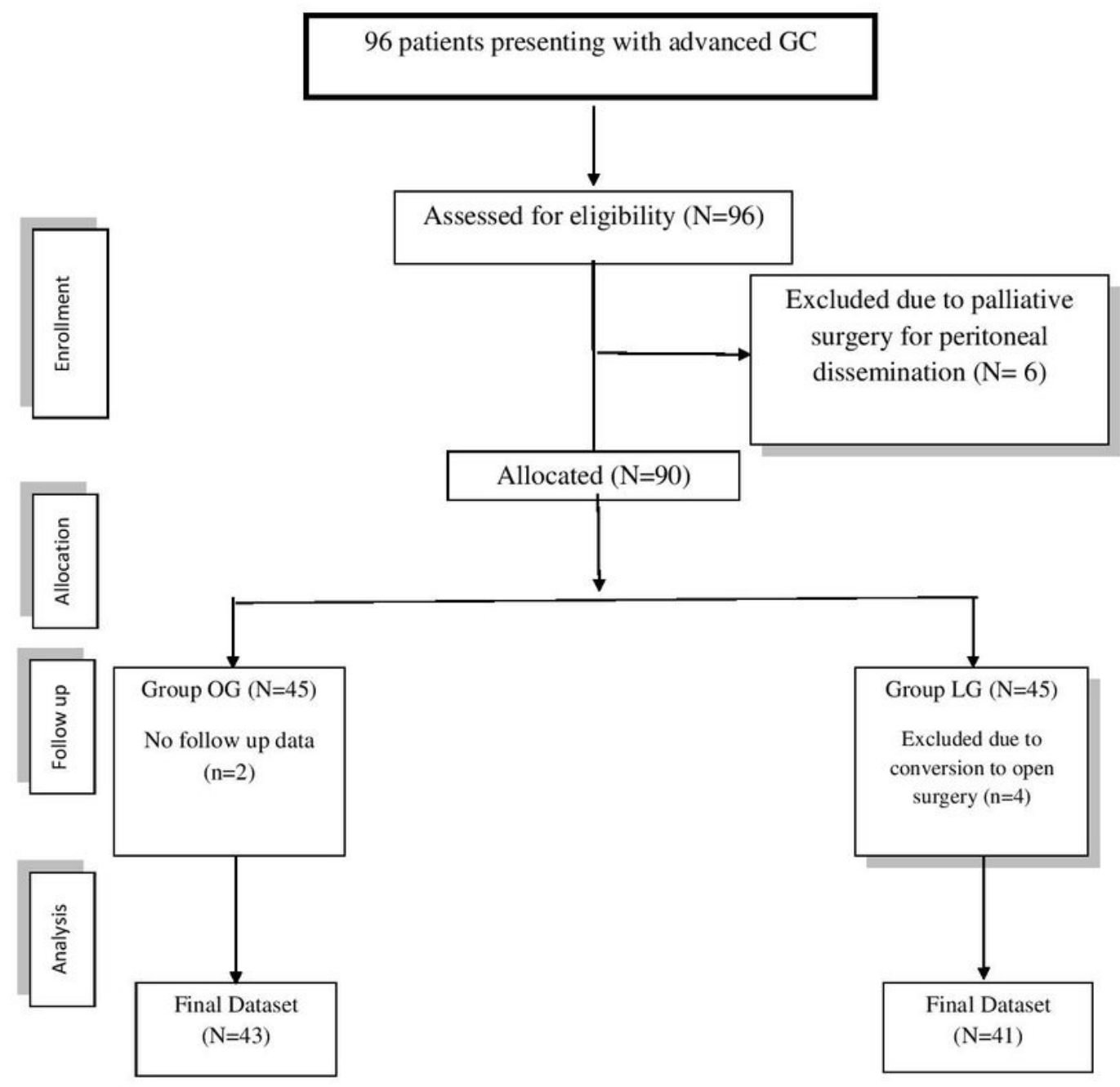

Figure 1

Study flowchart 


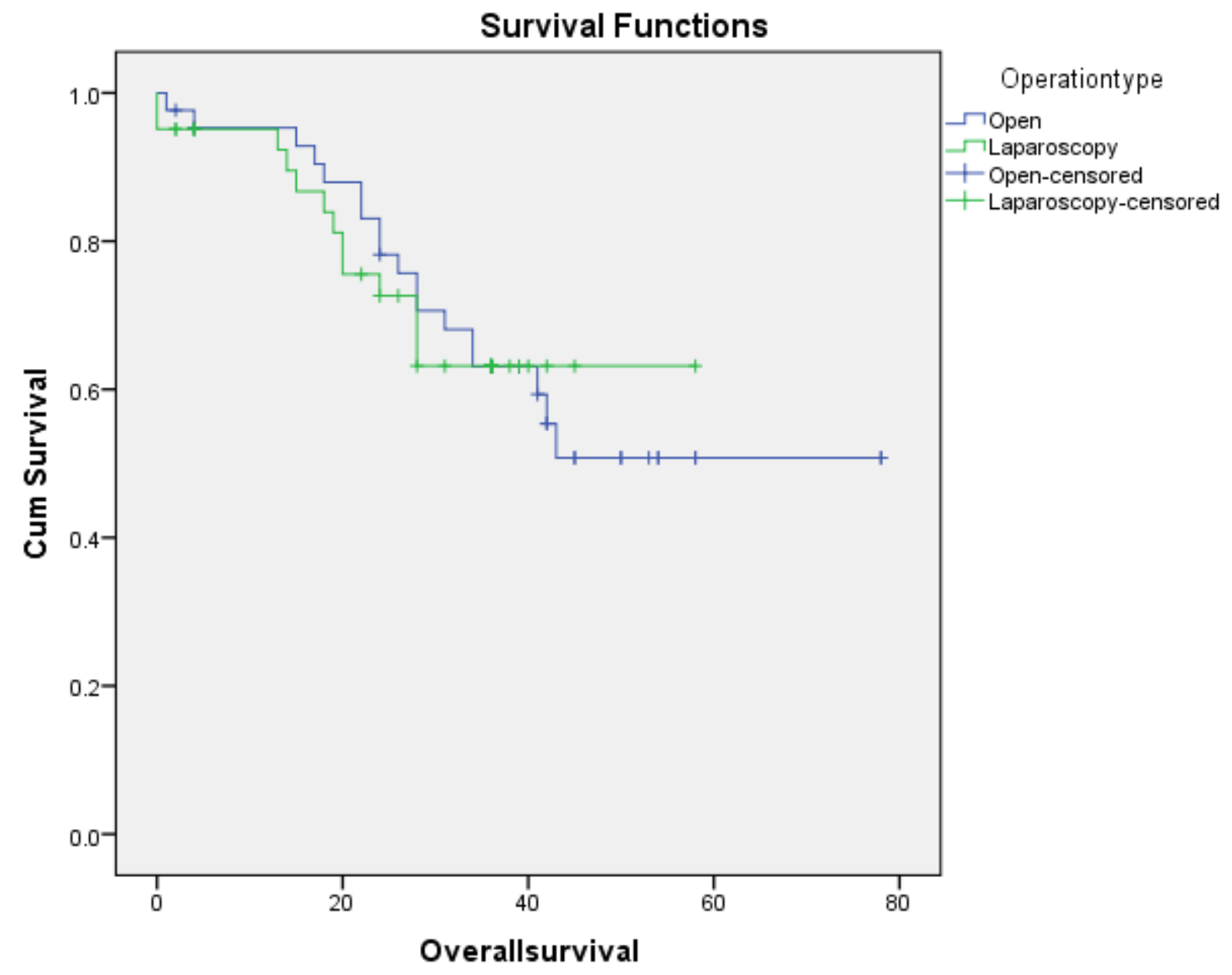

Figure 2

Kaplan-Meier curve showing overall survival. 


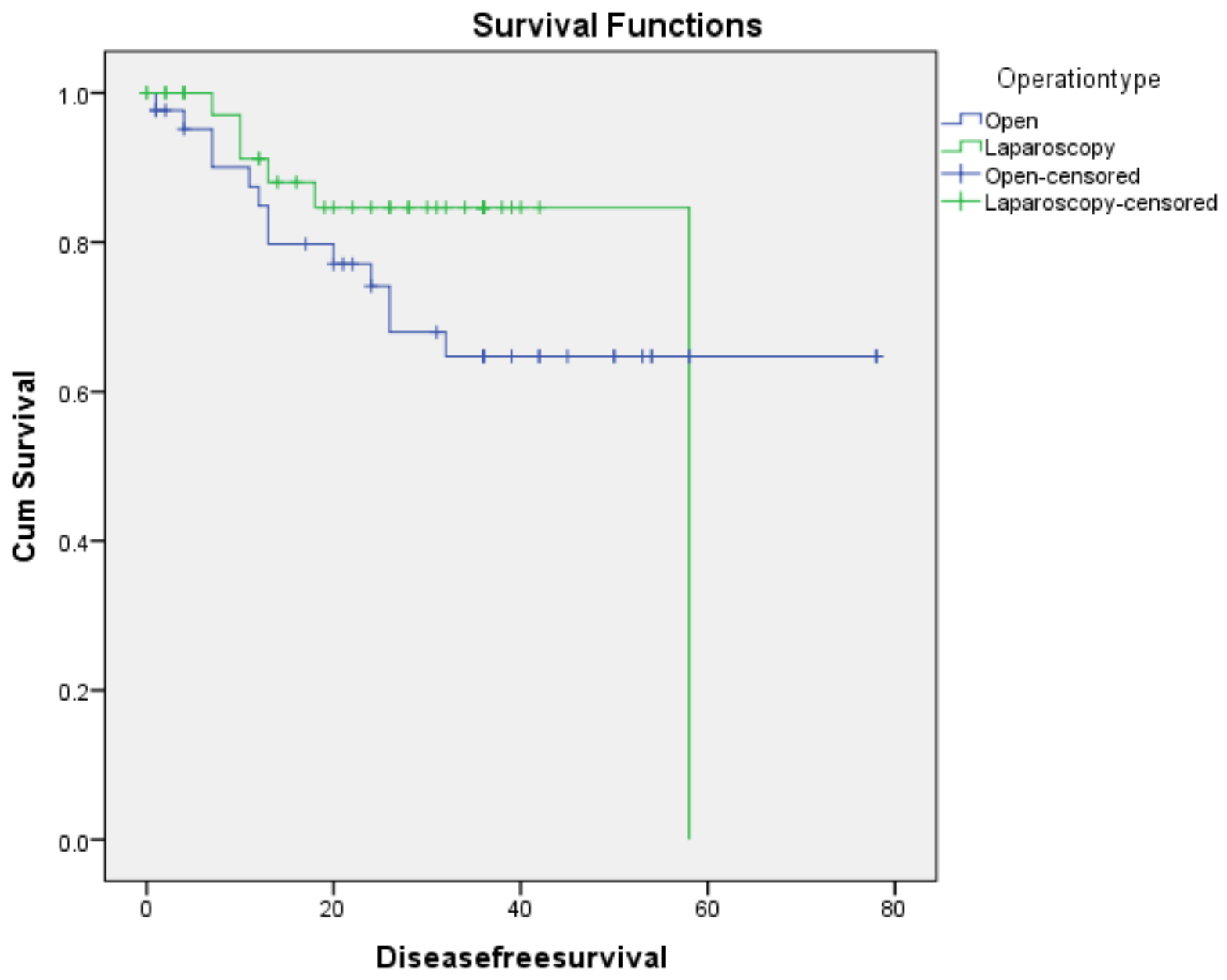

Figure 3

Kaplan-Meier curve showing disease progression-free survival

\section{Supplementary Files}

This is a list of supplementary files associated with this preprint. Click to download.

- SupplementaryNo1.docx

- replytemplate.doc 